Original Research Article

\title{
Study of drug utilization pattern in the department of radiotherapy in a tertiary care teaching hospital
}

\author{
Chandan N. G. ${ }^{1 *}$, Ranganathan T. ${ }^{2}$, Nagabushan H. ${ }^{1}$
}

\begin{abstract}
${ }^{1}$ Department of Pharmacology, ${ }^{2}$ Department of Radiotherapy, Mandya Institute of Medical Sciences, Mandya, Karnataka, India
\end{abstract}

Received: 11 February 2019

Revised: 23 March 2019

Accepted: 03 April 2019

\section{*Correspondence to: \\ Dr. Chandan N. G., \\ Email: drchandanng81@ \\ yahoo.com}

Copyright: (C) the author(s), publisher and licensee Medip Academy. This is an openaccess article distributed under the terms of the Creative Commons Attribution NonCommercial License, which permits unrestricted noncommercial use, distribution, and reproduction in any medium, provided the original work is properly cited.

\begin{abstract}
Background: Drug utilization studies are an important tool in evaluating the rationality of therapeutic practice and also it is said to improvise the therapeutic use of drugs. The present study will be undertaken to evaluate the drug utilization pattern in the department of Radiotherapy.

Methods: This was a prospective, observational study that was undertaken in the department of Radiotherapy in a tertiary care teaching hospital. The study was conducted for a period of 6 months after obtaining permission from Institutional Ethical Committee. The study was conducted among cancer patients undergoing radiotherapy. The data was collected from the patient case records and was analyzed as per the WHO prescribing indicators.

Results: In the present study it was observed that the average number of drugs prescribed per encounter was 7.7. The drugs prescribed by generic name were $41.4 \%$. Percentage of encounters with an antibiotic prescribed was 100 . Percentage of encounters with an injection prescribed was $20.5 \%$. Percentage of drugs prescribed from essential drugs list was $35.8 \%$.

Conclusions: Drug utilization studies helps in modifying the prescription pattern and helps in making the drug usage more rational.
\end{abstract}

Keywords: Drug utilization studies, Essential drugs, Radiotherapy, WHO prescribing indicators

\section{INTRODUCTION}

Cancer is a term used for diseases in which cells abnormally divides without control and are able to invade other tissues. ${ }^{1}$ It is a major public health problem and is among the leading causes of morbidity and mortality. ${ }^{2}$ It has been projected by World Health Organization that number of new cancer cases are said to increase by more than $80 \%$ by 2030 in low income countries. An estimated 10 to 11 million patients with cancer diagnosis each year by 2030 is projected by the WHO in low- and middleincome countries. ${ }^{3}$ Various modalities of treatment for cancer include surgery, radiotherapy and chemotherapy. ${ }^{2}$
Radiotherapy is now an important non-surgical cancer therapy used in more than $50 \%$ of all patients with cancer whether curative or palliative. ${ }^{4}$ Radiotherapy involves use of high dose radiation to kill the cancer cells and at the same time normal cells which are adjacent to cancer cells getting exposed to radiation is minimised..$^{5}$

Cytotoxic effects produced by radiation involve absorption of radiation by the DNA of the cells which results in ionization of atoms in DNA and its damage. ${ }^{6}$ Radiotherapy is usually associated with numerous side effects which are site dependant. Some of the acute adverse effects associated with radiotherapy include erythema, dermatitis, hair loss, diarrhea and cystitis. Late complications include 
fibrosis which can result in bowel or urethra obstruction following pelvic tumor irradiation and hardening in the breast following radiotherapy for breast cancer. Radiation induced emesis is another commonly seen adverse effect more often seen in upper abdomen irradiation and total body irradiation. ${ }^{7,8}$

Drug utilization research has been developed not only to evaluate the rationality in therapeutic practice, but it also helps in improving therapeutic use of drugs and also to evaluate the cost-effectiveness of the treatment. Drug usage pattern and trend can also be evaluated by conducting drug utilization studies. ${ }^{9}$

The present study will be undertaken to evaluate the drug utilization pattern in the department of Radiotherapy.

\section{METHODS}

This was a prospective, observational study that was undertaken in the department of Radiotherapy in the teaching hospital attached to Mandya Institute of Medical sciences after getting the approval of Institutional Ethical Committee. The study was conducted from April 2016 to September 2016 for a period of 6 months.

\section{Study population}

The study was conducted among cancer patients undergoing radiotherapy.

\section{Inclusion criteria}

- Cancer patients of either sex who were aged 18 years and above undergoing radiotherapy

- And giving consent to participate in the study.

\section{Exclusion criteria}

Patients less than 18 years and those not consenting to participate in the study.

\section{Study procedure}

The case records of the patients fulfilling the inclusion criteria were reviewed. The data collected included demographic information like patient's age, gender, occupation, and drug prescription which includes the drugs prescribed, dosage form and frequency. All the information was recorded in a specially designed proforma. The data was analyzed as per the WHO prescribing indicators as follows. ${ }^{10}$

- Average number of drugs per encounter

- Percentage of drugs prescribed by generic name

- Percentage of encounters with an antibiotic prescribed

- Percentage of encounters with an injection prescribed

- Percentage of drugs prescribed from essential drugs list.

\section{Statistical analysis}

After collection of data it was entered in Microsoft excel sheet and evaluated using descriptive statistics. The results were expressed in numbers and percentages.

\section{RESULTS}

A total of 78 patients receiving radiotherapy were included in the study. Among them 42 (53.8\%) were females and 36 $(46.1 \%)$ were males patients.

In the present study it was observed that among 78 patients receiving radiotherapy $21(26.9 \%)$ patients were diagnosed with carcinoma cervix, $15(19.2 \%)$ patients with breast carcinoma, $11(14.1 \%)$ patients with hypopharyngeal malignancy and $9(11.5 \%)$ patients with oropharyngeal carcinoma. Among female patients receiving radiotherapy $50 \%$ of them had carcinoma cervix followed by $35.7 \%$ with breast carcinoma, $7.1 \%$ with oesophageal carcinoma, $4.7 \%$ with carcinoma glottis and $2.3 \%$ with endometrial carcinoma. Among male patients receiving radiotherapy $30.5 \%$ had hypopharyngeal carcinoma, followed by $25 \%$ of them with oropharyngeal carcinoma, $19.4 \%$ with carcinoma tongue, $13.8 \%$ with carcinoma glottis, $5.5 \%$ with carcinoma tonsil and $2.7 \%$ each with oesophageal carcinoma and carcinoma maxilla (Figure 1 and 2).

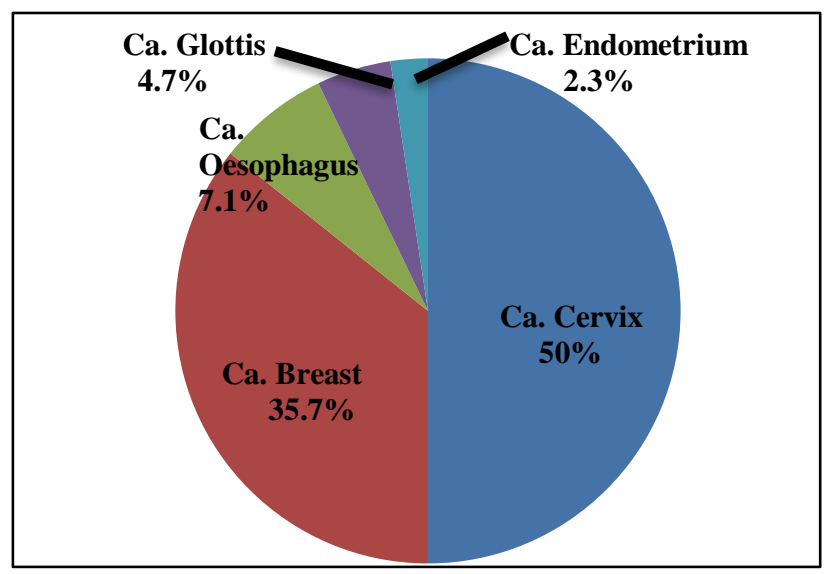

Figure 1: Distribution of cancer in females.

In the present study it was observed that all the patients on radiotherapy received NSAIDs and oral formulation of aceclofenac was the most commonly used NSAID which was used in combination with paracetamol and serratiopeptidase which constituted $10.5 \%$ of the drugs used. Around 12 patients received diclofenac in combination with serratiopeptidase. Opioid analgesic, tramadol was used in 8 cases as oral formulation. Injectable diclofeanc was used in $12.8 \%$ of the cases and $7.6 \%$ cases received injectable tramadol, an opioid analgesic. Antihistamine, cetirizine in tablet form was used in combination with montelukast in all the cases. Also, protein supplements and haematinics were prescribed for all the cases. Among PPIs, omeprazole (7.5\%) was commonly used. Among corticosteroids, topical 
preparations were prescribed more commonly (5.5\%). Clobetasol cream in combination with gentamicin was prescribed in 18 cases and topical triamcinolone for 11 patients. Deflazacort in the form of tablet was used in 12 cases. Amoxycillin (11.5\%) and metronidazole (11.5\%) were the antibiotics that were encountered more frequently.

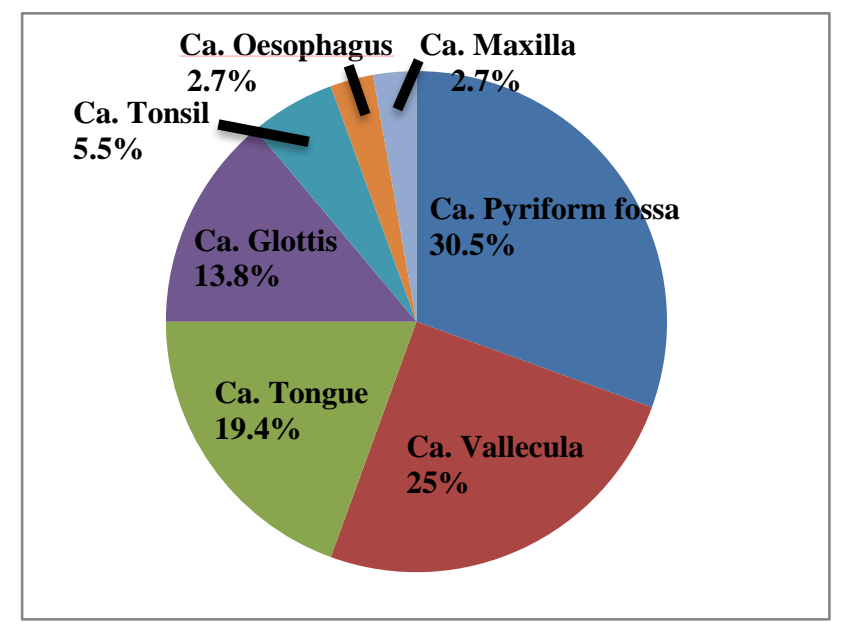

Figure 2: Distribution of cancer in males.

Table 1: WHO prescribing indicators.

\begin{tabular}{|ll|}
\hline WHO prescribing indicators & Results \\
\hline $\begin{array}{l}\text { Average number of drugs per } \\
\text { prescription }\end{array}$ & 7.7 \\
\hline $\begin{array}{l}\text { Percentage of drugs prescribed by } \\
\text { generic name }\end{array}$ & 41.4 \\
$\begin{array}{l}\text { Percentage of encounters with an } \\
\text { antibiotic prescribed }\end{array}$ & 100 \\
\hline $\begin{array}{l}\text { Percentage of encounters with an } \\
\text { injection prescribed }\end{array}$ & 20.5 \\
\hline $\begin{array}{l}\text { Percentage of drugs prescribed from } \\
\text { essential drug list }\end{array}$ & 35.8 \\
\hline
\end{tabular}

Table 2: Percentage of drugs prescribed from different classes.

\begin{tabular}{|lll|}
\hline Drug class & Frequency & Percentage \\
\hline $\begin{array}{l}\text { Nutritional } \\
\text { supplements }\end{array}$ & 156 & 25.6 \\
\hline Antibiotics & 148 & 24.3 \\
\hline Analgesics & 100 & 16.4 \\
\hline Antihistaminic & 78 & 12.8 \\
\hline PPIs & 74 & 12.1 \\
\hline Corticosteroids & 41 & 6.7 \\
\hline Miscellaneous & 11 & 1.8 \\
\hline
\end{tabular}

A total of 608 drugs were prescribed during the study period. Average number of drugs prescribed per encounter was 7.7 in this study. The drugs prescribed by generic name were $41.4 \%$ in present study. It was also observed that $20.5 \%$ of the prescriptions had a prescription for injection. Also, it was observed that $35.8 \%$ of the drugs prescribed were found in Essential list of medicines (Table 1).
In this study, it was observed that among the different class of drugs prescribed nutritional supplements were prescribed more frequently followed by antibiotics, analgesics, antihistaminics, Proton pump inhibitors (PPIs) and corticosteroids (Table 2).

\section{DISCUSSION}

The present study was conducted to evaluate the drug usage in the department of radiotherapy. During the study period of six months, of the total patients included in the study receiving radiotherapy, majority were females with cervical malignancy as the commonest type of cancer. Among male patients' head and neck malignancy was more common.

The average number of drugs prescribed per prescription was 7.7. Although, it appears as polypharmacy it is important to know that the definition of polypharmacy is variable and may vary with clinical setting. Polypharmacy is said to not only increase irrational use of drugs but also can increase the risk of drug interactions, medication errors and adverse effects. ${ }^{11,12}$ In present study it was observed that the percentage of drugs prescribed by generic name was $41.4 \%$. Use of generic drugs is said to decrease the expenditure of medicine. ${ }^{13}$ Also, various studies have shown that the generic drugs are comparable with that of the branded drugs. ${ }^{14}$ Hence the prescribing of generic drugs has to be encouraged.

Prescription of FDCs was also observed in the present study. Usage of FDCs can be beneficial as they can improve patient compliance by decreasing pill burden, reduced side effects and cost. Also, they may produce synergistic effect when used appropriately. Whereas, inappropriate FDCs may result in drug interactions and dose titration of individual ingredient will not be possible. Also, they can result in increased side effects and decreased effectiveness. ${ }^{15}$

The percentage of drugs prescribed from National list of essential medicine, 2015 was 35.8. ${ }^{16}$ Prescription of FDCs has reduced the percentage of drugs from Essential drug list used to some extent in this study. Prescribing drugs from essential drug list promotes rational use of drugs. Selection of drugs from the list of essential medicine assures safety and provides maximum benefits at a lower cost. ${ }^{17}$ There is a scope for improvement with regard to the selection of drugs from essential drug list.

Antibiotics were used in almost all the patients in this study. The usage of antibiotics was found to be higher in comparison with other similar study done in radiation oncology. ${ }^{18}$ Indiscriminate use of antibiotics increases the risk of drug resistance. ${ }^{19}$ Hence, the usage of antibiotics needs to be judicious.

In present study it was observed that most of the patients were prescribed with analgesics to treat skin reaction causing pain and also to treat cancer pain. Both NSAIDs 
and Opioid analgesics were used depending on the intensity of pain. NSAIDs like Paracetamol with aceclofenac were used more frequently in the treatment of pain. Opioid analgesic like tramadol was also used in some cases to get relief from pain.

WHO has recommended an analgesic ladder in the treatment of cancer pain, which suggests to begin the treatment with non-opioids and then to introduce mild opioids if required. If these drugs are not sufficient to treat the pain, strong opioid analgesics like morphine are recommended..$^{20}$

In the present study it was also observed that corticosteroids were another major class of drugs that was prescribed. Topical formulations were used more commonly than systemic formulations.

Various studies have shown the effectiveness of topical steroidal preparations in decreasing the acute dermatitis due to radiotherapy. ${ }^{21,22}$

Antihistamine was another commonly used class of drugs as observed in this study. Pruritus may be experienced by patients receiving radiotherapy. ${ }^{23}$ Antihistamines may be used in the treatment of pruritus.

The limitations of the study were that the study was conducted for a short duration. Data collected for an extended period will give a better result. Also, the Prescribing indicators are of less help in specialty outpatient setup, as the drug usage in such setup may be more complex. Thorough analysis of the information is required to confirm the rationality of the drug use as prescribing indicators alone may not be adequate.

\section{CONCLUSION}

This study has generated information with regard to the utilization of drugs in the department of radiotherapy. There appears to be some scope for improvement in the prescription pattern with respect to some of the prescribing indicators. Drug utilization studies helps in modifying the prescription pattern and helps in making the drug usage more rational.

\section{Funding: No funding sources}

Conflict of interest: None declared

Ethical approval: The study was approved by the Institutional Ethics Committee

\section{REFERENCES}

1. Kumar V, Abbas AK, Aster JC. Robbin's basic pathology. 10th ed. Philadelphia: Elsevier Saunders; 2018:189-242.

2. Cancer. Available at: https://www.who.int/en/newsroom/fact-sheets/detail/cancer. Accessed 30 January 2018.
3. Cancer. Available at: https://www.who.int/cancer/resources/keyfacts/en/. Accessed 30 Janyary 2018.

4. Aliyu UM, Jimoh AO, Yunusa A, Umar M. Pattern of Cancers Treated with Radiotherapy in Uduth Sokoto: A New Center Experience. J Clin Diagn Res. 2015;9(8):XC01-4.

5. Baskar R, Lee KA, Yeo R, Yeoh KW. Cancer and radiation therapy: current advances and future directions. Int J Med Sci. 2012;9(3):193-9.

6. Yoshimura M, Itasaka S, Harada $H$, Hiraoka $M$. Microenvironment and radiation therapy. BioMed research international. 2012;2013.

7. West CM, Barnett GC. Genetics and genomics of radiotherapy toxicity: towards prediction. Genome Med. 2011;3(8):52.

8. Berkey FJ. Managing the adverse effects of radiation therapy. Am Fam Physician. 2010;82(4):381-88.

9. Shalini S, Ravichandran V, Mohanty BK, Dhanaraj SK, Saraswathi R. Drug utilization studies - An overview. Int J Pharmaceut Sci Nanotechnol. 2010;3(1):803-10.

10. How to Investigate Drug Use in Health Facilities: Selected Drug Use Indicators - EDM Research Series No. 007: Chapter 2: Core drug use indicators: Group 1: Prescribing indicators. Available at: http://apps.who.int/medicinedocs/en/d/Js2289e/3.htm 1. Accessed 22 December 2018.

11. Rodrigues MCS, Oliveira C. Drug-drug interactions and adverse drug reactions in polypharmacy among older adults: an integrative review. Rev Latino-Am Enfermagem. 2016;24:e2800.

12. Masnoon N, Shakib S, Kalisch-Ellett L, Caughey GE. What is polypharmacy? A systematic review of definitions. BMC Geriatr. 2017 Dec;17(1):230.

13. Cameron A, Laing R. Cost savings of switching private sector consumption from originator brand medicines to generic equivalents. World Health Report. 2010;35:210-5.

14. Bera A, Mukherjee A. The importance of generic drugs in India. Int $\mathbf{J}$ Pharm Chem Biol Sci. 2012;2(4):575-87.

15. Gupta YK, Ramachandran SS. Fixed dose drug combinations: Issues and challenges in India. Indian J Pharmacol. 2016 Jul;48(4):347.

16. National List of Essential Medicine. 2015. Available at: http://cdsco.nic.in/WriteReadData/NLEM2015/NLEM,\%202015.pdf Accessed 22 December 2018.

17. Bansal D, Purohit VK. Accessibility and use of essential medicines in health care: Current progress and challenges in India. J Pharmacol Pharmacotherapeut. 2013 Jan;4(1):13.

18. Sneha G, Aparna S, Sri Lakshmi BNVB, Varma AS, Naidu DSR. Adjunctive Drug Utilization Pattern in Oncology Department of A Teritiary Care Hospital in South India. Indo Am J Pharm Res. 2015:5(03).

19. Ventola CL. The antibiotic resistance crisis: part 1: causes and threats. Pharma Therapeut. 2015;40(4):277. 
20. WHO's cancer pain ladder for adults. Available at: https://www.who.int/cancer/palliative/painladder/en/. Accessed 21 December 2018.

21. Bostrom A, Lindman H, Swartling C, Berne B, Bergh J. Potent corticosteroid cream (mometasone furoate) significantly reduces acute radiation dermatitis: results from a double-blind, randomized study. Radiother Oncol. 2001;59(3):257-65.

22. Ulff E, Maroti M, Serup J, Falkmer U. A potent steroid cream is superior to emollients in reducing acute radiation dermatitis in breast cancer patients treated with adjuvant radiotherapy. A randomised study of betamethasone versus two moisturizing creams. Radiother Oncol. 2013;108(2):287-92.

23. Yonova D. Pruritus in certain internal diseases. Hippokratia. 2007 Apr;11(2):67.

Cite this article as: Chandan NG, Ranganathan T, Nagabushan H. Study of drug utilization pattern in the department of radiotherapy in a tertiary care teaching hospital. Int $\mathrm{J}$ Basic Clin Pharmacol 2019;8:945-9. 